\title{
On sulphocyanuret and bisulphuret of ethyle
}

\section{Auguste Cahours}

To cite this article: M. Auguste Cahours (1847) On sulphocyanuret and bisulphuret of ethyle, Philosophical Magazine Series 3, 30:198, 67-68, DOI: 10.1080/14786444708562628

To link to this article: http://dx.doi.org/10.1080/14786444708562628

曲 Published online: 30 Apr 2009.

Submit your article to this journal $\sqrt{3}$

Џ Article views: 2

Q View related articles $₫$ 
come over at about $270^{\circ} \mathrm{F}$.; the temperature at which the last portion comes over may amount to $280^{\circ} \mathrm{F}$.

The preparation of this product is difficult on account of the bumping of the liquid, which sometimes comes over. It must be heated slowly, and the retort should be ten times larger than required to contain the liquid.

Sulphocyanuret of methyle, after it has been purified by digestion over chloride of calcium and rectification, has the following properties : it is a colourless and very limpid liquid; it has an alliaceous odour; its vapour is unpleasant and it stupefies; it boils steadily at about $270^{\circ} \mathrm{F}$. Its density is 1.115 at about $61^{\circ} \mathrm{F}$. Water dissolves a very small portion, but it nevertheless acquires its odour; it combines with alcohol and æether in all proportions.

In diffused light chlorine acts very slowly upon it, producing fine crystals of chloride of cyanogen; and at the same time there is formed a large quantity of a heavy yellow oil, which solidifies when in contact with ammonia.

Potash scarcely acts upon it in the cold. A solution when heated decomposes it, and there are formed ammonia and bisulphuret of methyle; the residue contains cyanuret of potassium and carbonate of potash.

Solution of ammonia alters it readily, giving rise to a brown substance analogous to ulmine, and a small quantity of a crystallized white matter. Heated in an alcoholic solution, the sulphocyanuret of methyle is decomposed ; there are produced bisulphuret of methyle and sulphocyanuret of potassium, easily recognised by the persalts of iron. Moderately concentrated nitric acid dissolves it when heated, but it separates entirely on cooling.

By analysis it appears to consist of-

$$
\begin{array}{rrrr}
\mathrm{C}^{8} \ldots \ldots \ldots \ldots & 300 \cdot 0, \text { or in } 100 & 32.87 \\
\mathrm{H}^{6} \ldots \ldots \ldots \ldots & 37.5 & \ldots & 4.11 \\
\mathrm{~N}^{2} \ldots \ldots \ldots \ldots & 177.0 & \ldots & 19.18 \\
\mathrm{~S}^{2} \ldots \ldots \ldots \ldots & 400 \cdot 0 & \ldots & 43.84 \\
& \ldots & &
\end{array}
$$

The mean of two experiments gave 2.559 as the density of its vapour; whereas, supposing its molecule to yield four volumes of vapour, calculation would give 2537.-Ann. de Ch. et de Ph., Novembre 1846 .

\section{ON SULPHOCYANURET AND BISULPHURET OF ETHYLE. BY M. AUGUSTE CAHOURS.}

Sulphocyanuret of Ethyle.-By distilling a mixture of sulphovinate of lime and persulphuret of potassium, both solutions being concentrated, a yellowish liquid is obtained, which after washing with water, digesting on chloride of calcium, and cautious rectification, becomes a colourless and very limpid liquid, the odour of which resembles that of sulphocyanuret of methyle. Its density is 1.020 at about $61^{\circ} \mathrm{F}$. It is insoluble in water, but alcohol and æther dissolve it in 
all proportions. It acts similarly to sulphocyanuret of methyle upon reagents.

Chlorine and bromine act energetically on the sulphur compounds of methyle and of etlyyle. With bromine perfectly well-crystallized combinations are obtained.

By analysis this substance appears to he composed of -

$$
\begin{aligned}
& \text { C1. .... 450.0, or in } 100 \text { parts } 41 \cdot 38
\end{aligned}
$$

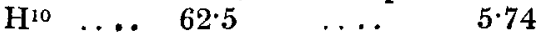

$$
\begin{aligned}
& \mathrm{N}^{2} \ldots \ldots 1177 \cdot 0 \quad \ldots \ldots \quad 16.09 \\
& S^{2} \ldots \ldots \frac{400 \cdot 0}{1089 \cdot 5} \quad \ldots . \quad \frac{36.79}{100 \cdot 00}
\end{aligned}
$$

By experiment the density of the vapour of this substance was found to be 3.018 , while calculation would lead to 3.032 , supposing the molecule represented four volumes of vapour.

Bisulphuret and Tersulphuret of Ethyle.-The former was obtained in considerable quantity by distilling a mixture of sulphovinate of lime and persulphuret of potassium; but towards the end of the rectification of the rough product there came over a yellowish and slightly volatile liquid, which gave by analysis results which tended to show that it was to be considered as a tersulphuret of ethyle.

M. Cahours analysed the bisulphuret of ethyle, and his results agreed precisely with those previously obtained by M. P. Morin, $\mathrm{C}^{8} \mathrm{H}^{10} \mathrm{~S}^{2}$. The density of its vapour was found by experiment to be $4 \cdot 270$, and by calculation $4 \cdot 240$, on the supposition that the molecule of this compound furnishes two volumes of vapour.

Chlorine vividly acts upon the two compounds above described; moderately concentrated nitric acid does the same, a portion of the sulphur being converted into sulphuric acid: there is also produced an acid susceptible of forming soluble and crystallizable salts with potash, barytes, and oxide of lead.-Ann. de Ch. et de Phys., Novembre 1846 .

\section{ANALYSIS OF THE WHITE DIOPSIDE.}

M. Hermann found this substance from Achmatowsk to consist of-

$$
\begin{array}{lrr}
\text { Silica } \ldots \ldots \ldots \ldots \ldots \ldots \ldots & 53.97 \\
\text { Lime } \ldots \ldots \ldots \ldots \ldots \ldots & 25.60 \\
\text { Magnesia. } \ldots \ldots \ldots \ldots \ldots & 17.86 \\
\text { Protoxide of iron. . . . . } & 2.00 \\
\text { Protoxide of manganese } \ldots & 0.57 \\
\hline
\end{array}
$$

This analysis corresponds to the formula $\mathrm{Si}^{4} \mathrm{M}^{4} \mathrm{O}^{6}$ : $\left[\mathrm{Si}^{4}\left(\mathrm{Ca}^{2}\right.\right.$ $\left.\mathrm{Mg}^{2}\right) \mathrm{O}^{6}$ ].-Journ. de Pharm. et de Ch., Novembre 1846.

\section{ANALYSES OF THE NATIVE PHOSPHATES OF COPPER.}

BY M. HERMANN.

The phosphates of copper do not occur more extensively anywhere than in the mines of Nischnotaglisk in the Uralian Moun- 